\title{
Los manuscritos encuadernados de José Martínez de Arce (ca. 1662-1721)
}

\section{Bounded manuscripts of José Martínez de Arce (ca. 1662-1721)}

\author{
Clara Mateo Sabadell \\ Universidad Internacional de Valencia \\ mateo.clara@gmail.com
}

\section{RESUMEN}

En el Archivo de Música de la Catedral de Valladolid se conservan cuatro manuscritos encuadernados en muy buen estado, con signaturas Ms. 7, Ms. 8, Ms. 22 y Ms. 231. Se trata de cuatro fuentes únicas para el estudio de villancicos y cantatas, que fueron escritos por José Martínez de Arce, maestro de capilla en la catedral de Valladolid desde 1690 hasta el año de su muerte, acaecida en diciembre de 1721.

Estos manuscritos, todavía poco estudiados, son una herramienta fundamental no solo para conocer más de 300 obras escritas en ellos por Martínez de Arce, sino también para fecharlas y, en última instancia, para conocer cómo funcionaba la mente del compositor a la hora de crear. Su estudio supone un reto, ya que el orden de las piezas que contienen es aparentemente aleatorio. Este artículo pretende dar a conocer en detalle estas fuentes, teniendo en cuenta tanto el continente como el contenido.

Palabras clave: José Martínez de Arce, archivo de música catedral de Valladolid, villancico, cantata, siglo dieciocho.

\section{Abstract}

The Music Archive of the Valladolid cathedral keeps among its treasures four bounded manuscripts (Ms. 7, Ms. 8, Ms. 22 and Ms. 23), that contain villancicos and cantatas written by José Martínez de Arce. He was chapel master at this cathedral from 1690 until he died in december 1721.

${ }^{1}$ El material de partida para la elaboración de este artículo procede de mi tesis doctoral: Mateo Sabadell, C. (2016): El cambio de estilo en los villancicos de José Martínez de Arce (ca. 1662-1721). Valladolid: Tesis doctoral inédita. Se puede descargar en http://uvadoc.uva.es/handle/10324/16710 


\section{Clara Mateo Sabadell}

These four volumes are yet to be studied. They hold more than 300 works written by Arce. Besides, their study will enable to date some of these works and, at the same time, it will allow the researcher to know more about how the composer's mind worked. This study is also a methodological challenge, because the order of the works is, apparently, random. The main goal of this article is to study these musical sources, analyzing their content, and describing them as music containers.

Key words: José Martínez de Arce, villancico, cantata, 18th Century, music archive of Valladolid Cathedral.

Mateo Sabadell, C. (2018). Los manuscritos encuadernados de José Martínez de Arce (ca. 16621721). Cuadernos de Investigación Musical, 4, 5-31.

doi: http://dx.doi.org/10.18239/invesmusic.v0i4.1814

\section{INTRODUCCIÓN}

La música compuesta por José Martínez de Arce asciende a un total aproximado de 880 obras, la mayoría villancicos en romance, aunque también tiene repertorio en latín que está todavía por estudiar. Arce vivió plenamente la etapa de cambio que sufrió España en 1700, cuando la guerra de sucesión terminó con el fin de la dinastía de los Austrias y Carlos II se vio sustituido como rey por el nieto del Rey Sol: Felipe V. Estos cambios políticos tuvieron como consecuencia la llegada a la corte de músicos italianos y franceses, que influyeron en el estilo tradicional que hasta el momento se escuchaba en los villancicos. José Martínez de Arce se hizo eco de estos cambios, pero de una manera personal y propia, convirtiéndose en "bilingüe" y mezclando ambos estilos de manera original.

Los soportes en los que se conserva esta abundante producción son variados: papeles sueltos, juegos de partichelas y cuatro manuscritos encuadernados con las signaturas Ms. 7, Ms. 8, Ms. 22 y Ms. 23. El primero contiene 98 obras, el segundo 111, el tercero tiene 23 y el cuarto 75. En total, los cuatro contienen 304 obras, que suponen el 34\% de las obras catalogadas del compositor. ¿Por qué estudiar solo los manuscritos encuadernados? Porque los propios soportes son ya un objeto de estudio, desde el punto de vista de su génesis, pero, sobre todo, porque estos volúmenes presentan varias incógnitas sobre su contenido y el criterio que siguió el compositor ${ }^{2}$ para rellenarlos, características que los convierten en un óptimo objeto de estudio.

La mención a estos cuatro manuscritos en la bibliografía existente es escasa y dispersa. En el primer inventario realizado por Anglés en Anuario Musical solamente aparece un somero índice de los manuscritos Ms. 7 y Ms. 8 (Anglés, 1948: 68-75). Martín Moreno, en el volumen de Alianza correspondiente a la música española del siglo XVIII, presentó de forma somera estos dos mismos volúmenes, sin mencionar los otros dos (Martín Moreno, 1985: 112-113). Fue Carmelo Caballero en la voz Martínez de Arce, José, del $D M E H$, quien habló por vez primera de los manuscritos Ms. 22 y Ms. 23, de los que no

\footnotetext{
${ }^{2}$ Se supone que fue el propio compositor el copista de estos manuscritos por la similitud de grafías entre estas fuentes y las manos de borrador conservadas, que en muchos casos llevan su firma.
} 
Los MANUSCRitos ENCUADERnAdos DE José MARTÍNEZ DE ARCE (CA. 1662-1721)

daba signatura, ya que se limitó a hablar de que «la reciente aparición de dos nuevos manuscritos autógrafos [...] incrementa sensiblemente el número de obras conservadas» (Caballero, 1999: 273-275). Juan José Carreras, en la voz Cantata del NG tuvo en cuenta también los volúmenes que contenían cantatas, sobre todo el Ms. 23. Sin embargo, solo los estudia de forma somera, ya que su objetivo es ofrecer una visión general del panorama de la cantata española barroca (Carreras, 2001: 37-40). Por último, está la referencia que hace a los manuscritos López-Calo en el volumen I de su catálogo del archivo de música de la catedral de Valladolid (López-Calo, 2001). En él se limita a dar una sucinta descripción, así como a catalogar las obras que contiene. No obstante, pasa por alto algunas obras que están escritas aprovechando pentagramas sueltos de algunas páginas. Tampoco ofrece al investigador el cruce de referencias que promete, ya que muchas veces no hace constar la existencia de partichelas de algunas obras que cataloga. Por último, en mi tesis doctoral realicé un estudio exhaustivo de estos manuscritos encuadernados (Mateo Sabadell, 2016). Sin embargo, no fueron mi objeto de estudio principal y, por esta razón, aparecen de forma dispersa a lo largo del trabajo. Este hecho hace que se pierda la profundidad que puede dar un análisis conjunto de estos cuatro manuscritos encuadernados.

El objetivo del presente artículo es comprender cuál fue la génesis de estas fuentes, vistas desde la doble perspectiva del contenido y el continente. Mediante este enfoque será posible fechar algunas de las obras, partiendo del uso de las fuentes como herramienta de datación.

En primer lugar, se presenta el contexto de estas cuatro fuentes, entendiendo por tal al compositor de las obras que contienen, José Martínez de Arce, y a la producción global de éste, para ver qué lugar ocupan los cuatro volúmenes encuadernados. Después, se irán presentando los manuscritos, pero no siguiendo un orden lineal, sino por parámetros que ayuden a responder a varias preguntas de investigación. La primera es: ¿Cómo fueron elaborados los manuscritos, qué proceso de copia se siguió? Conocer la respuesta a esta pregunta servirá para responder a la segunda: ¿Se pueden fechar las obras contenidas en los manuscritos en función del puesto que ocupan en el libro? De esta manera, se conseguirá una visión más profunda, que se perdería con una descripción lineal.

\section{JosÉ MARTíNEZ de ARCE (CA. 1662-1721) Y LOS MANUSCRITOS ENCUADERNADOS DENTRO DE SU PRODUCCIÓN CONSERVADA}

Para poner un marco que permita al lector conocer el contexto de creación de los cuatro manuscritos encuadernados objeto de estudio, se presenta muy brevemente tanto al compositor de las obras en ellos contenidos, como el panorama de soportes que éste utilizó a lo largo de su carrera compositiva.

La catedral de Valladolid fue el centro de trabajo de José Martínez de Arce durante treinta años. Accedió al puesto el 28 de septiembre de 1690, tras la muerte de Miguel Gómez Camargo, acaecida en abril de ese mismo año. No hay constancia en las Actas Capitulares de que superara un examen de oposición. Tampoco se han encontrado menciones a recomendación alguna. Simplemente, consta la incorporación de Martínez de 


\section{Clara Mateo Sabadell}

Arce, que venía de Segovia, donde había ejercido como maestro de capilla ${ }^{3}$. Dato curioso es que a dicho puesto tampoco accedió previa oposición. En las actas capitulares segovianas solo consta su nombramiento el día 17 de febrero de 1687, donde se aclara que Arce es uno «de los propuestos para ello, y para que habían escrito de diferentes iglesias para serlo de ésta» ${ }^{4}$. Todo apunta a que provenía de Madrid, donde seguramente tuviera un protector que le ayudara a acceder a estos puestos catedralicios.

Esta aparente facilidad de acceso a dos magisterios consecutivos resulta llamativa, por el contraste que presentan con la capilla en la que creció como niño de coro y en la que aprendió composición: la de la catedral de Orense. Si bien no se ha encontrado una partida de nacimiento concluyente, todo apunta a que José Martínez de Arce nació en Orense, seguramente en $1662^{5}$. Lo que sí es claro es que pasó allí sus años como niño de coro. También es probable que aprendiera composición con Martín de San Román.

La razón por la cual Arce se fue a Madrid en vez de convertirse en sucesor de su maestro cuando éste murió, puede extraerse de las actas, donde se lee que fue sustituto pero nunca llegó a ser sucesor. El Cabildo le pidió que compusiera obras para la fiesta de San Martín, para ganar tiempo y cubrir la demanda de obras para la festividad del 11 de noviembre. El proceso de oposición tuvo lugar el día 12 de diciembre. Se presentaron Arce y Antonio Rodríguez de Vega, quien fue elegido el día 14 «por mayor parte de votos» ${ }^{6}$.

Se sabe que Arce se fue a Madrid tras suspender la oposición gracias a que su hermano, Tomás, se quedó en la catedral de Orense unos meses más. Tomás Martínez de Arce aparece desde fechas muy tempranas siempre junto a José. En Orense no hay constancia de la fecha de admisión, pero se le menciona ya junto a su hermano en la entrada del 11 de enero de 1678, cuando ambos recibieron seis ducados por haber «trabajado mucho en estas Pascuas» ${ }^{7}$. Desde entonces, siempre estuvo junto a su hermano, con quien seguramente se reunió en Madrid tras abandonar la catedral de Orense, aunque en las actas no se menciona su partida.

Una vez que se conocen a grandes rasgos los hitos de la vida del compositor ${ }^{8}$, el siguiente paso es situar los manuscritos en el contexto más amplio de las obras fechadas, en todos los soportes. Esto tiene como finalidad establecer una cronología aproximada de las obras que contienen. A la vez, es un primer paso para respaldar una ulterior propuesta de datación para algunas obras contenidas en los manuscritos.

\footnotetext{
3 Posesión del señor José Martinez de Arce, maestro de capilla. Archivo Catedral de Valladolid, Actas Capitulares, vol. 6 (1670-1703), 28-09-1690.

${ }^{4}$ Archivo Catedral de Segovia, Actas Capitulares, vol. 18, 17-02-1687.

${ }^{5}$ La partida de bautismo no es concluyente, porque si bien los nombres de los progenitores, el lugar y la fecha coinciden, el nombre del bautizado es «Josepha» y no José. Para más detalles véase: Mateo, 2016: 16-19.

${ }^{6}$ Archivo Catedral Orense, Actas Capitulares, vol. 17, f. 195, 06-12-1685.

7 Archivo Catedral Orense, Actas Capitulares, vol. 17, f. 2v, 11-01-1678.

${ }^{8}$ Para más información sobre la vida de este maestro de capilla véase Mateo Sabadell, C. (2016). El cambio de estilo en los villancicos de José Martínę de Arce (ca. 1662-1721). Valladolid: Tesis doctoral inédita.
}

Cuadernos de Investigación Musical, 2018, junio, $\mathrm{n}^{\circ}$ 4, págs. 5-31.

ISSN: 2530-6847

DOI: http://dx.doi.org/10.18239/invesmusic.v0i4.1814 
Los MANUSCRitos ENCUADERnAdos DE José MARTÍNEZ DE ARCE (CA. 1662-1721)

Las obras con fechas correspondientes a la etapa orensana, madrileña y segoviana (1680-1690) están todas recogidas en formato de papeles sueltos ${ }^{9}$. Lo mismo sucede con las compuestas durante la primera década del magisterio vallisoletano. Sin embargo, como se puede ver en el gráfico de la Fig. 1, desde 1699 hasta 1710 el 90\% de las obras están recogidas en dos manuscritos encuadernados: en el Ms. 7 (63\%) y en el Ms. 8 (27\%).

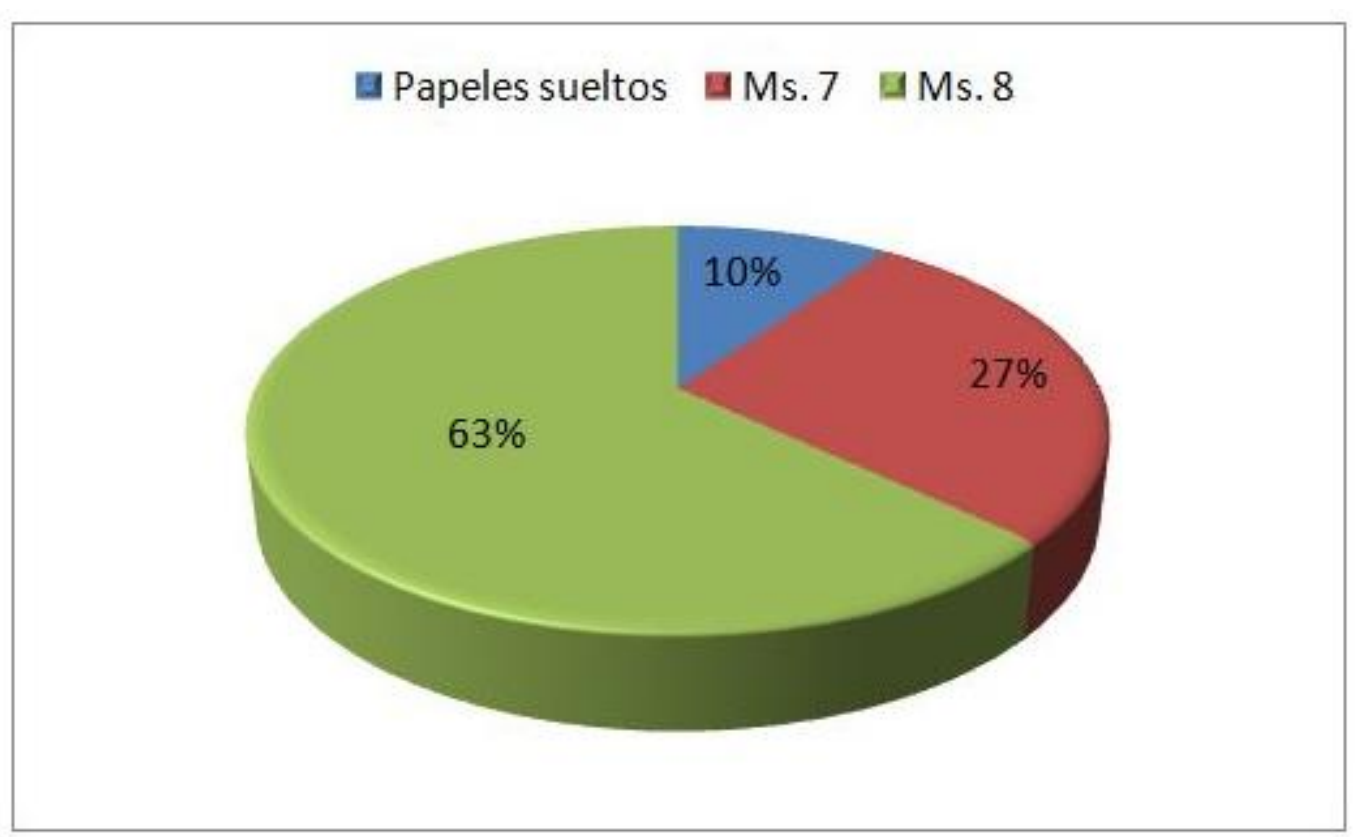

Fig. 1: La música en las fuentes entre 1699 y 1710 (Elaboración propia).

Entre 1710 y 1717 el panorama cambió y se hizo mucho más variado, en lo que a uso de soportes se refiere. En el gráfico que se incluye a continuación (Fig. 2A) se puede ver cómo la gran mayoría de las obras (fechadas) de este periodo se conservan en formato de papeles sueltos, tanto manos de borrador $(62 \%)$ como partichelas (11\%). El uso del Ms. 8 fue casi inexistente (1\%) y el del Ms. 7 se redujo de manera considerable (hasta un 12\%). Por otro lado, hizo su aparición el Ms. 22, que contiene un 14\% de las obras fechadas entre 1710 y 1717.

Un análisis más profundo de la distribución de las obras en las fuentes a partir de 1710, revela algo cercano a un patrón. En la Fig. 2B, se muestra un gráfico que detalla la distribución de las obras en cada año. En él se puede ver cómo desde 1710 hasta 1713 la gran mayoría fueron escritas en manuscritos encuadernados. Sin embargo, a partir de 1714 fueron más numerosos los papeles sueltos. Lo más seguro es que esto se debiera a la crisis económica que se manifestó en una reforma de mesadas de los músicos, en la que se rebajó el sueldo a gran parte de la capilla ${ }^{10}$.

\footnotetext{
${ }^{9}$ La denominación de «papeles sueltos» se ha utilizado de manera genérica para denominar a todos aquellos papeles que no están encuadernados: tanto manos de borrador como partichelas.

${ }_{10}$ Reforma. Archivo Catedral Valladolid, Actas Capitulares, vol. 7 (1704-1737), f. 161, 30-01-1714.
} 
Clara Mateo SABADEll

A. Visión general de la distribución de la música en las fuentes (1710-1717)

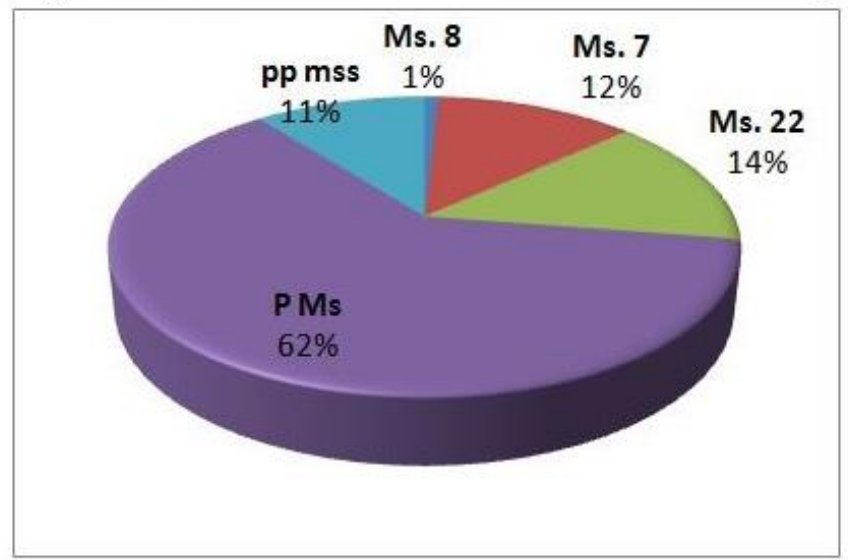

B. Distribución por años

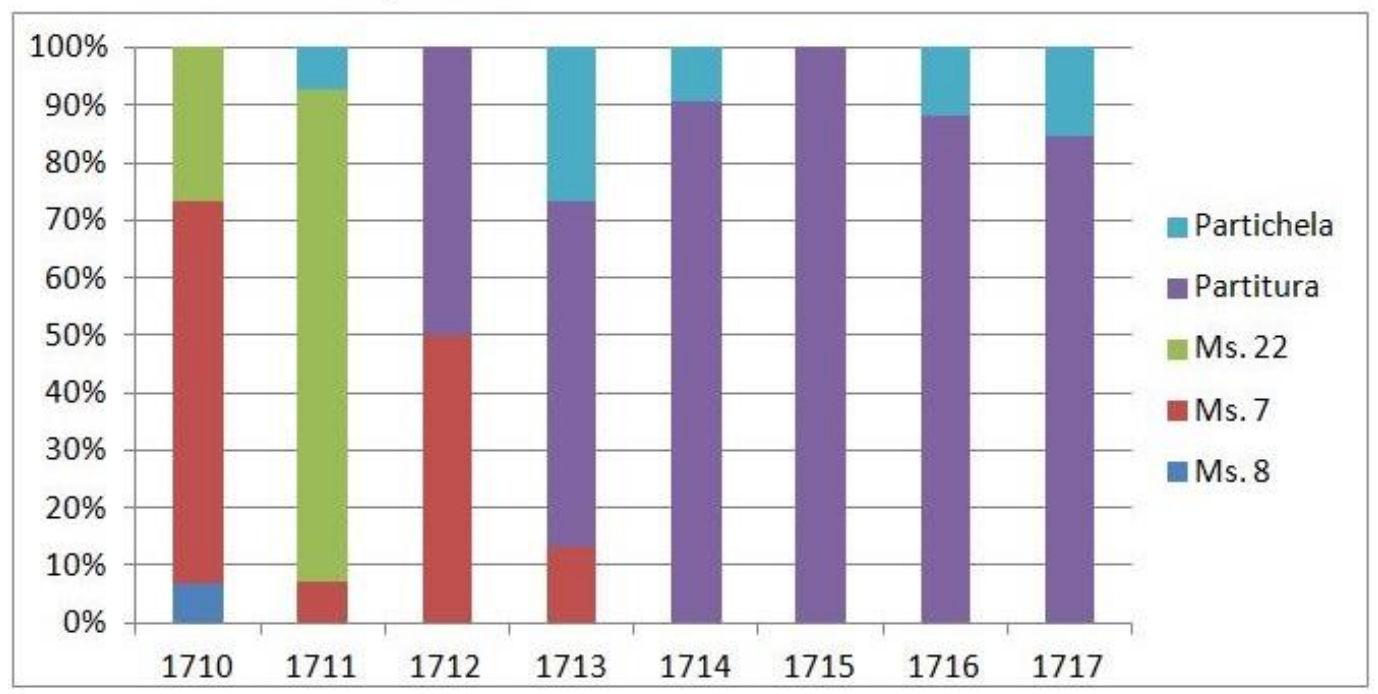

Fig. 2: La música en las fuentes entre 1710 y 1717 (Elaboración propia).

En los cuatro últimos años de su vida, José Martínez de Arce volvió a disponer de un manuscrito encuadernado, con signatura Ms. 23, donde se conserva el 78\% de las obras con estas fechas. En el desglose por años se puede ver cómo la gran mayoría de obras en otros formatos tienen fecha de 1718 (Fig. 3). 
A. Visión general de la distribución de la música en las fuentes (1718-1721)

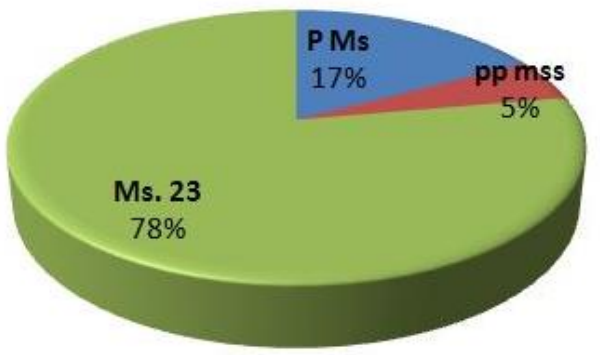

B. Distribución por años

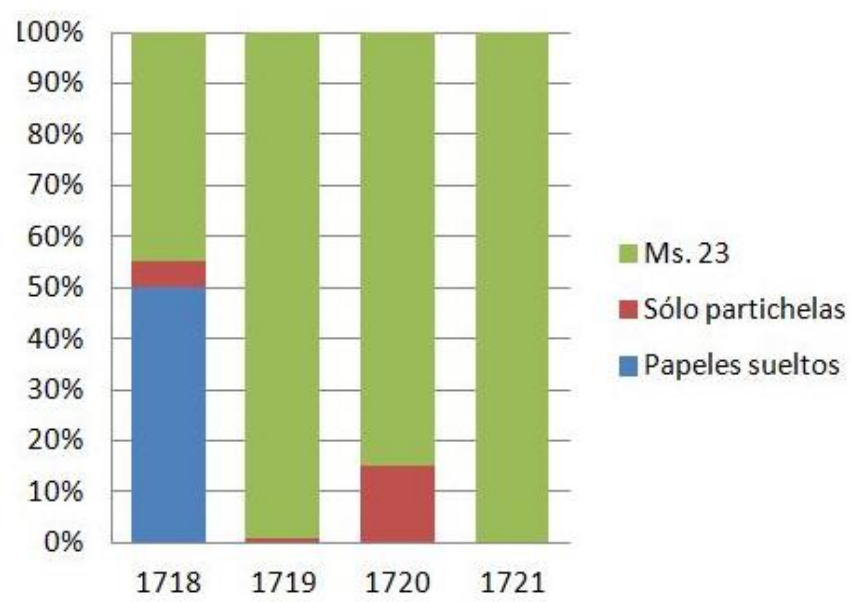

Fig. 3: La música en las fuentes entre 1718 y 1721 (Elaboración propia).

La carencia obvia del enfoque aportado por la tabla es que la visión que ofrece es sesgada, ya que solo trabaja con las obras fechadas. El estudio detallado de los manuscritos busca tener más datos objetivos, que sirvan como elemento de datación para obras que están sin fechar.

Antes de proceder al estudio, cabe en este punto preguntarse las razones que en esta época llevaban a los maestros de capilla a elaborar un libro manuscrito de partituras. De las tipologías propuestas por Ezquerro (2001) en su artículo «Casos curiosos, peculiaridades y formas alternativas de anotar la música en el área hispánica del siglo XVII. Procesos de intercambio entre lo culto y lo popular», con la que mejor encajarían los libros aquí estudiados sería la de copia "de archivo". Hay varias características que coinciden con la descripción que da Ezquerro, quien afirma que se tratan de "copias manuscritas de buena calidad "sacadas" expresamente para ser custodiadas y bien conservadas en el archivo de música catedralicio", con el fin de hacer copias de la música que contienen cuando sea necesario (p. 2). No obstante, otra peculiaridad de este tipo de copias es que presentan cada voz "de corrido", es decir, que no discurren todas de forma paralela, sino una detrás de otra, con la finalidad de facilitar el trabajo al copista de partichelas. Eso no sucede en ninguno de los cuatro manuscritos, que parecen más bien la recopilación de manos de 


\section{Clara Mateo Sabadell}

borrador, unas más cuidadas que otras, copiadas por el propio compositor, en los que constan todas las voces organizadas en sistemas, es decir, ya juntas y en sentido vertical.

Dos son las razones que respaldan la hipótesis de que se tratan de copias autógrafas. La primera es la firma que aparece en la esquina superior derecha de muchas composiciones, cuya grafía es similar a la de otros muchos borradores sin encuadernar conservados en el archivo. La segunda es la similitud de la grafía musical de los manuscritos encuadernados con los borradores en formato de papeles sueltos. No obstante, queda pendiente un estudio comparativo más profundo como el que realiza Yáñez en su tesis doctoral sobre las fuentes del Archivo de Música las Catedrales de Zaragoza para el estudio de las sonatas de Domenico Scarlatti (2016).

La finalidad de los manuscritos encuadernados que protagonizan el presente artículo es análoga a la descrita en el tipo de copia indicado por Yáñez en la p. 193 de su tesis doctoral: "la [copia] realizada por los compositores para poner en papel sus propias obras". Por otro lado, en la Fig. 4. se puede ver cómo las características que cita Yáñez (p. 196) como indicativas de que se trata de una copia realizada por el compositor coinciden, en parte, con las de los manuscritos: tachones, pentagramas vacíos al final de algunos folios, folios en blanco, empleo de caligrafía rápida (aunque dependiendo de los casos, hay veces en que se trata más bien de una caligrafía esmerada, o por lo menos, más que en las manos de borrador sin encuadernar).

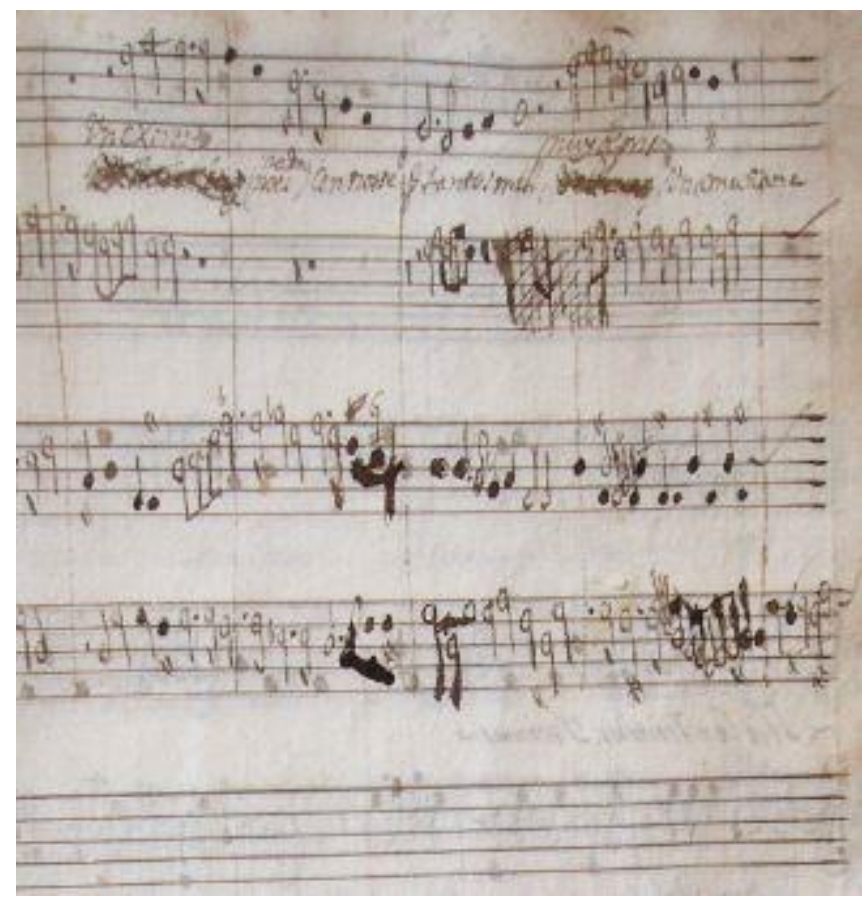

Fig. 4. Ejemplo de folio con tachones y parte del folio en blanco. (E-Vc Ms. 22, folio 29). 
Los MANUSCRitos ENCUADERnAdos DE José MARTÍNEZ DE ARCE (CA. 1662-1721)

\section{DESCRIPCIÓN Y ANÁlisis DE RASgos EXTERnOS PARA SABER SI SE TRATA DE COMPENDIOS O CUADERNOS}

La primera incógnita que presentan estas fuentes es: cuál fue su génesis. Las dos opciones más obvias son que estos manuscritos sean una recopilación de papeles sueltos, unidos a posteriori, o que se trate de cuadernos en blanco (o rayados), en los que el compositor fue escribiendo.

Para responder a esta primera pregunta, se ha estudiado los cuatro manuscritos desde el punto de vista del soporte, es decir, entendidos como continente. El orden seguido para abordar todos estos aspectos no es manuscrito por manuscrito, sino los parámetros a estudiar, del más general al más específico. Lo primero, las medidas y la encuadernación. Después, el interior, empezando por el número de folios y siguiendo por el aspecto y distribución de la música en los mismos.

\subsection{MEDIDAS Y ENCUADERNACIÓN}

Los manuscritos Ms. 7, Ms. 8 y Ms. 23 comparten muchos rasgos comunes en su aspecto externo. Las medidas son muy similares: 311x215 mm el Ms. 7, 308x217 mm el Ms. 8 y 315x215 mm el Ms. 23. Por otro lado, los tres están encuadernados en pergamino con un acabado muy parecido en las costuras (cuatro en forma de equis) y el color de la piel. Asimismo, los tres tienen una inscripción casi idéntica en el lomo, no sólo por el orden de las palabras y las abreviaturas, sino también por la grafía.

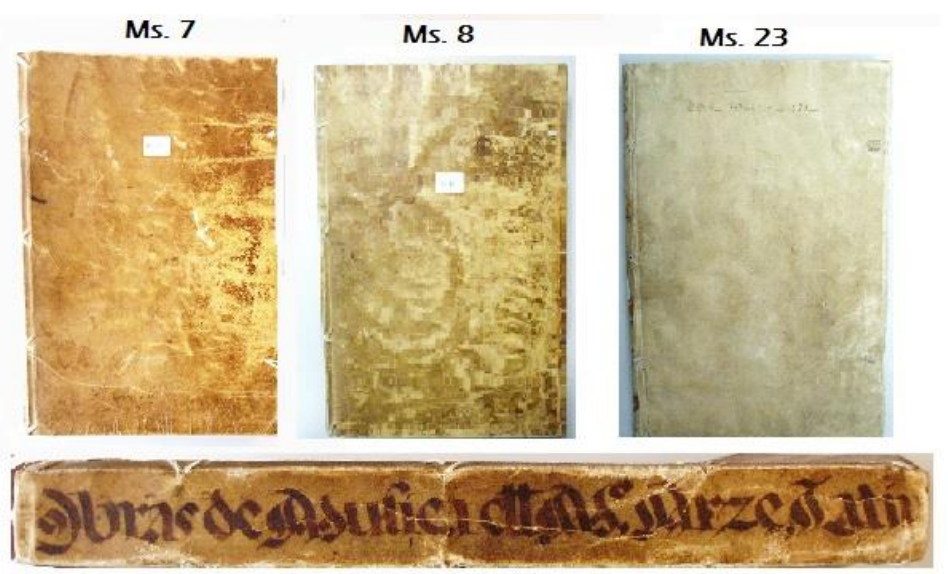

Ms. 7: Obras de Musica d[e]l M[aestr]o Arze, Latín

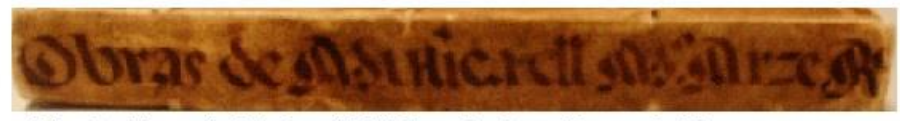

Ms. 8: Obras de Musica d[e]l M[aest]o Arze R[oman]c[e]

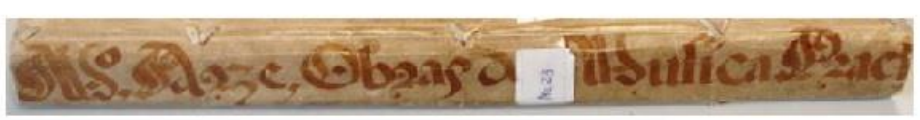

Ms. 23: M[aestr]o Arze Obras d[e] Musica Pract[ica]

Fig. 5. Aspecto externo de los manuscritos Ms. 7, 8 y 23 (Archivo de Música de la Catedral de Valladolid). 


\section{Clara Mateo Sabadell}

Como se puede ver en la figura, el Ms. 23 es el único que tiene una inscripción en la portada, que reza «Años| de 1718-719-720-721». La grafía de esta inscripción, así como la tinta y su grado de fusión con el pergamino apuntan a que es contemporánea al manuscrito. Tal vez fue hecha al terminarlo, aunque también cabe la posibilidad de que Arce fuera apuntando los años a medida que finalizaban. También es una posibilidad a tener en cuenta que, por lo menos en el caso de los manuscritos 7 y 8 , fueran un intento de confeccionar una colección o serie. Como se verá más adelante, la grafía de las obras que contienen, así como la encuadernación, son muy similares en uno y en otro, hecho que refuerza esta hipótesis.

Con respecto al Ms. 22, difiere mucho en su aspecto de los otros tres. Es ligeramente más alto que el resto, ya que mide 311×220 mm. Lo más llamativo es la encuadernación hecha con un pergamino utilizado anteriormente; el texto de la portada apunta a que tal vez provenga de un libro en latín. Sin embargo, aunque sí se puede intuir, los párrafos con tinta más clara y grafía cursiva están borrados. No se aprecia bien si esto se debe al desgaste producido por el uso y el paso del tiempo o a que fueron raspados, con la finalidad de reutilizar el pergamino a modo de palimpsesto. En la contraportada está escrito con letra más grande el comienzo del himno a los santos «Exultet caelum laudibus» (Fig. 6).
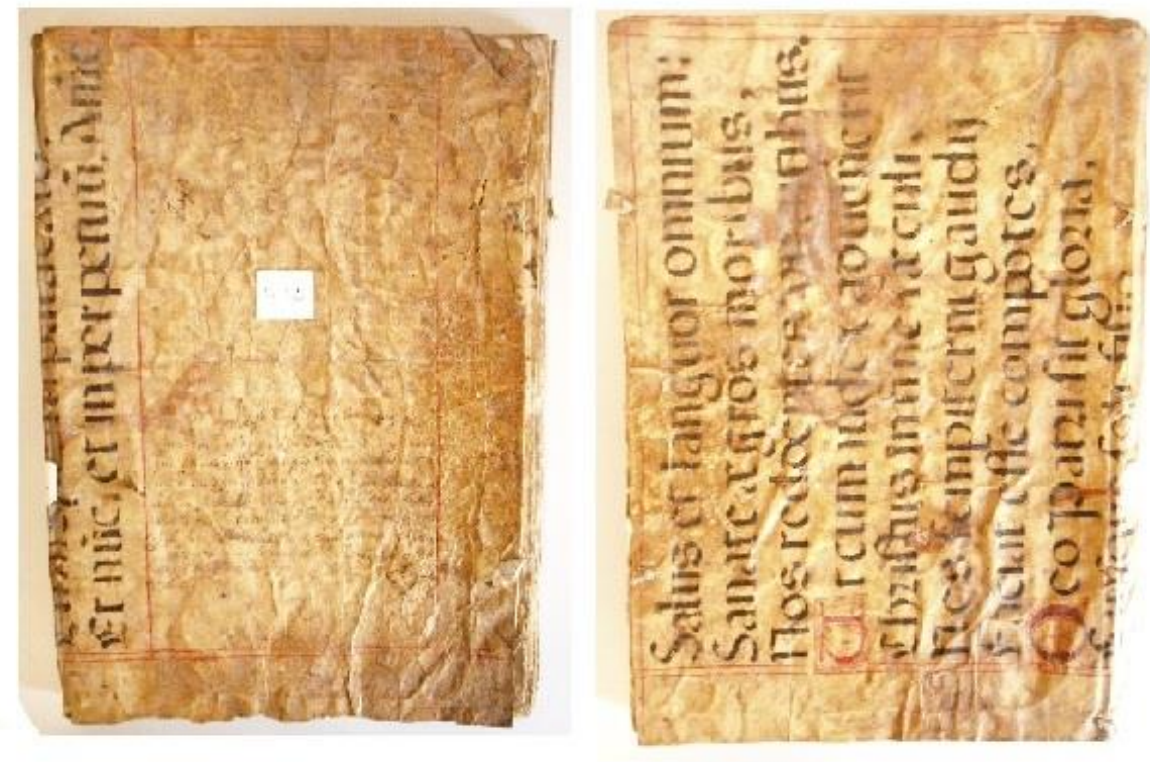

Fig. 6: Portada y contraportada del Ms. 22 (Archivo de Música de la Catedral de Valladolid).

El número de folios no es el mismo en todos los manuscritos. El más delgado es el Ms. 22, con tan sólo 84 folios. Le sigue el Ms. 23, con 178. Los otros dos manuscritos son sensiblemente más gruesos: con 220 folios el Ms. 7 y 246 el Ms. 8. El papel en todos es de buena calidad, dado que, a pesar de estar escritos por ambos lados, no se traspasa la tinta. Este hecho es también síntoma del bajo grado de acidez de esta última. Cabe destacar, por último, el mayor grosor de los folios del Ms. 22. 
LOS MANUSCRITOS ENCUADERNADOS DE JosÉ MARTÍNEZ DE ARCE (CA. 1662-1721)

El perfil de los cantos es irregular, porque el papel no fue guillotinado. Sin embargo, a pesar de este detalle, el canto superior de los manuscritos Ms. 7 y Ms. 8 tiene restos de pintura roja que indican que fueron decorados con este color. El Ms. 23 no está policromado.

Los manuscritos Ms. 7 y Ms. 8 también tienen anotaciones que parecen contemporáneas a su creación, pero ya en el interior. En la esquina inferior derecha de la guarda final del Ms. 8 está escrito: «Del pelícano sólo la fe». Más larga es la inscripción en el Ms. 7, que tiene escrito en la mitad superior del folio 220v:

Llevó D. Santiago para remitir al monasterio de Toro ocho villancicos de Santísimo, que fueron tres de a 6 y cinco de a 8, para este año de 1712. Villancicos para Ávila 1714: $1^{\circ}$ Muera la culpa, de violines y clarín; $2^{\circ}$ solo de violines, Ni el horror ni el susto; $3^{\circ}$ a 4, Oíd montes; $4^{\circ}$ solo de violines $A y$, dulces amores ${ }^{11}$.

Esta nota es una clara prueba de la circulación de repertorio y la interpretación de obras de Arce fuera del ámbito catedralicio pinciano. A ella habría que unir la anotación «Ávila» que aparece en la portada de veintisiete juegos de partichelas con fechas comprendidas entre 1692 y 1712. Seguramente, el vínculo con este centro fue el maestro de capilla Juan Cedazo, quien ejerció su magisterio en la catedral abulense desde 1685 hasta el año de su muerte, 1714. Ana $\mathrm{M}^{\mathrm{a}}$ Sabe Andreu en su estudio dedicado a la capilla de música de esta catedral hizo notar que este maestro descuidó en numerosas ocasiones su labor compositiva y pidió ayuda a otros compositores (Sabe Andreu, 2012: 265), entre los cuales se puede mencionar a José Martínez de Arce.

En cuanto a anotaciones más tardías, los manuscritos Ms. 7, 8 y 23 fueron foliados recientemente: los manuscritos Ms. 7 y Ms. 23 en la esquina superior derecha y el Ms. 8 en la inferior. Además, en la guarda inicial de dos de los manuscritos hay lo que parecen signaturas previas: «Ms. 20» para el Ms. 7 y Ms. 22 para el «Ms. 8».

En el Ms. 7 hay restos que indican que cuatro folios fueron arrancados entre el $32 \mathrm{y}$ el 33. La numeración correlativa indica que ya faltaban cuando se numeró el manuscrito. También cabe la posibilidad de que fueran arrancados al numerarse. El perfil irregular que se puede ver en el detalle de la figura incluida a continuación, muestra que fueron arrancados sin cuidado alguno. También se pueden apreciar indicaciones de voces como «G[enera $]$ l», o « $2^{\circ} \mathrm{Ch}^{\circ} »$, que el compositor no ponía cuando dejaba los folios en blanco. No obstante, en el único inventario previo al catálogo de López-Calo, no hay ninguna consignada ninguna obra nueva que no aparezca en el volumen actual (Anglés, 1948). Por lo tanto, lo más probable es que fueran cortados para usarlos como refuerzos para la encuadernación.

11 Dos de estos villancicos no se conservan y los otros dos están en formato de hoja suelta: Muera la culpa (1713, E-Vc 70/173, ff. 1-2r) y Ay, dulces amores (s.a., E-Vc 70/165). 
Clara Mateo SABADELL

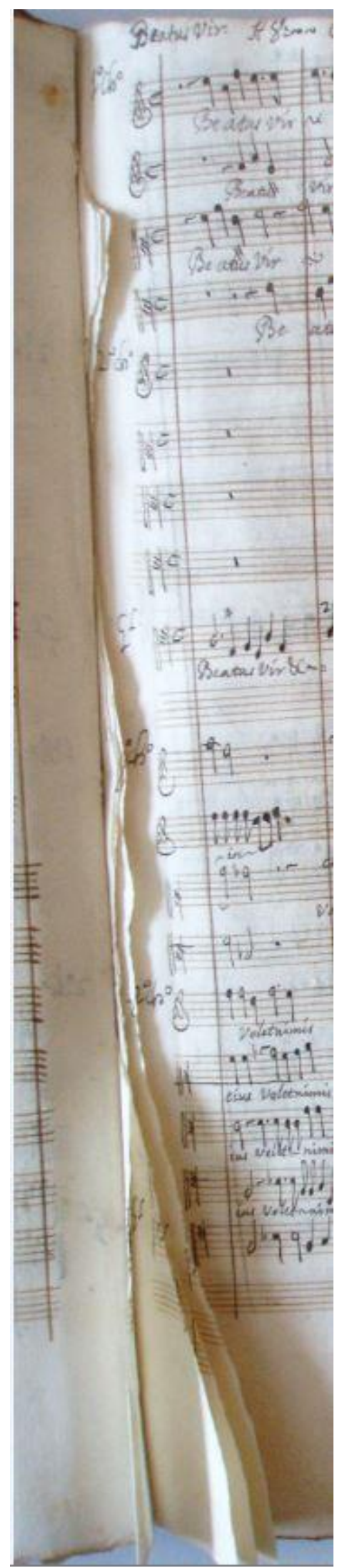

Fig. 7: Detalle de páginas arrancadas, Ms. 7, f. 33. (Archivo de Música Catedral de Valladolid). 


\section{LOS MANUSCRITOS ENCUADERNADOS DE JOSÉ MARTÍNEZ DE ARCE (CA. 1662-1721)}

Por lo tanto, los rasgos inmediatamente externos apuntan a que los manuscritos Ms. 7, 8 y 23 procedían de un mismo artesano, aunque el Ms. 23 no es tan grueso como los dos primeros. Por otro lado, el Ms. 22 presenta características muy diferentes, que hacen pensar que fue un cuaderno que Arce encontró a medio escribir y siguió usando para copiar sus obras $^{12}$.

Los datos obtenidos no permiten responder de manera rotunda a la pregunta planteada. Sin embargo, el hecho de que el Ms. 22 fuera un cuaderno que Arce encontró, lleva a pensar que la práctica habitual era encargar un libro en blanco, donde ir copiando las obras. No obstante, también cabe la posibilidad de que comprara los pliegos de papel y luego los encuadernara todos juntos. En cualquiera de los dos casos, la siguiente pregunta es si el papel estaba en blanco, o si lo vendían ya rayado. Para responder a la pregunta, nada mejor que los propios folios.

\subsection{LA COMPOSICIÓN DE LAS PÁGINAS PARA CONOCER EL TIPO DE PAPEL}

En este punto, los manuscritos Ms. 7 y Ms. 8 son casi idénticos, ya que el diseño de las páginas es muy similar. Esto se aprecia muy bien en los folios en blanco, como el que se muestra en la figura siguiente.

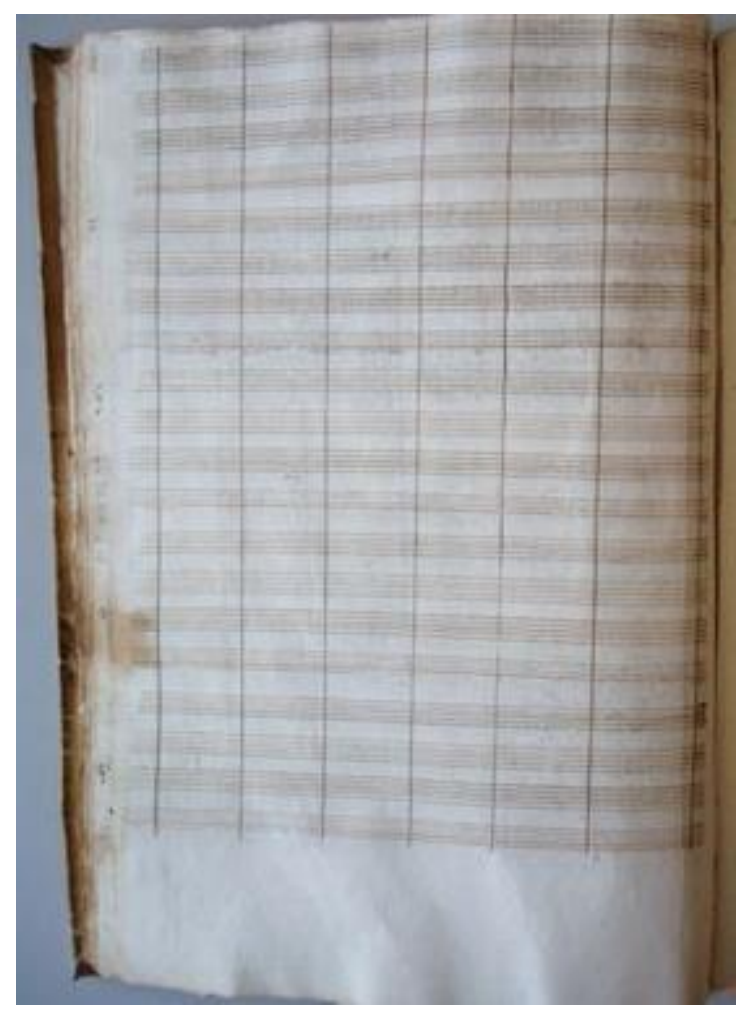

Fig. 8: Página en blanco del Ms. 7 (Archivo de Música Catedral de Valladolid).

\footnotetext{
12 La similitud de la grafía de este manuscrito y las manos de borrador, firmados y conservados todos en el mismo archivo, lleva a pensar que fue Arce el copista en todos los casos.
} 


\section{Clara MATeo SABADEll}

Como se puede ver en la Fig. 8, los márgenes superior izquierdo y derecho son casi inexistentes, mientras que el margen de abajo es mucho mayor y deja un gran espacio en blanco, posiblemente destinado a copiar el texto literario de más coplas, cuando se trataba de villancicos. Hay veinte pentagramas por página, con un rastro muy fino, separados a una distancia uniforme, que permitía después al compositor configurar los sistemas según las necesidades de cada obra. Otro elemento trazado previamente fueron las líneas verticales continuas que dividen a todos los pentagramas en seis compases, a los que se añadió un espacio menor al principio de cada uno para albergar la clave y el compás.

El manuscrito Ms. 23 es parecido a los dos anteriores, pero tiene una distribución algo diferente. Este hecho es interesante, ya que tal vez sea muestra de cómo las fuentes se adaptaban al tipo de música que contenían. Como se verá un poco más adelante, las obras que contiene este manuscrito no son solo villancicos, sino también cantatas. Éstas usaban una plantilla diferente a la policoral del repertorio más tradicional. Tal vez, por esta razón los folios del Ms. 23 contengan un menor número de pentagramas (16 frente a los 20 de los otros dos), separados de manera uniforme, pero sin estar agrupados en sistemas. El resto de las características es muy similar a los dos anteriores, por lo que no se redundará en ellas.

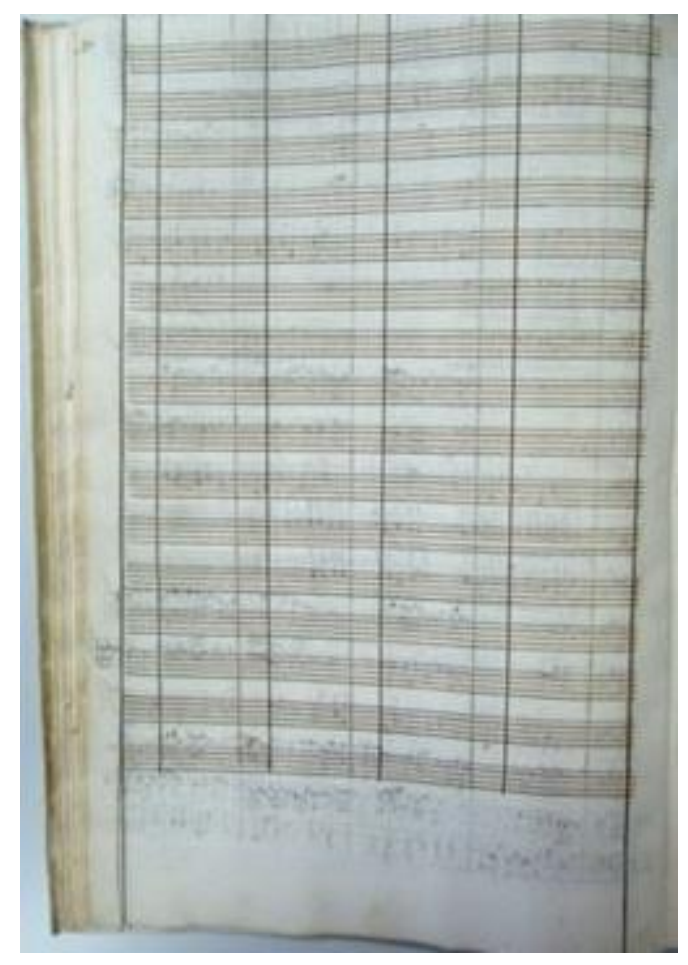

Fig. 9: Página en blanco del Ms. 23 (Archivo de Música de la Catedral de Valladolid).

De nuevo, el volumen distinto es el Ms. 22, cuyos pentagramas tienen un rastro mucho más amplio, hecho que hace que haya tan solo diez pentagramas por página, distribuidos de manera uniforme. Esto se debe, seguramente, a que el volumen fue concebido para anotar música monódica, como las obras en latín con las que comienza, a cuya escritura se adapta mucho mejor que a la forma de escribir más cursiva y menuda de 
Martínez de Arce, quien usa su grafía más esmerada ${ }^{13}$, pero no llega a llenar el espacio entre líneas.

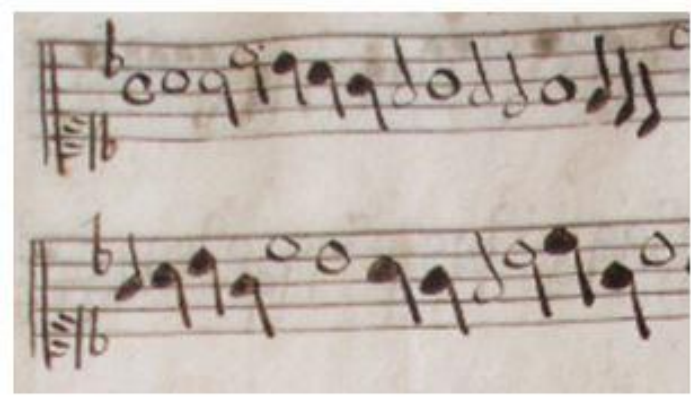

Latín (f. 1v)

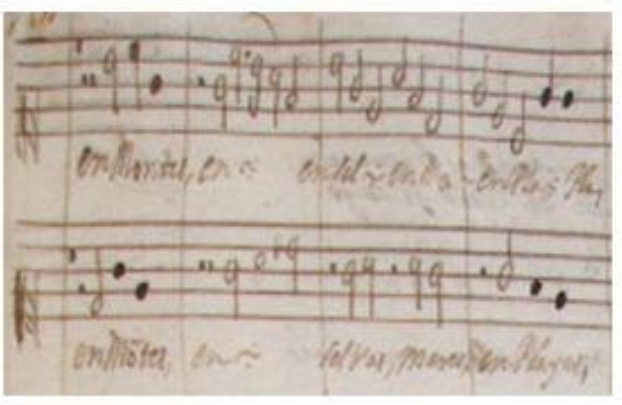

Castellano (f. $14 \mathrm{v})$

Fig. 10: Ejemplos de adaptación de grafías en el Ms. 22 (Archivo de Música de la Catedral de Valladolid).

Los rasgos externos de todos los manuscritos inclinan la balanza a favor de libros de papel pautado que Arce compró para escribir sus obras. No hay en los libros de fábrica ni en las actas ninguna mención a los volúmenes encuadernados. Lo más seguro es que los adquiriera a título personal, con el fin de disponer de un medio más cómodo de conservar sus composiciones, que después pasaron a ser propiedad de la catedral en virtud de su legado testamentario. Todo parece indicar que el Ms. 22 es bastante más antiguo y que los manuscritos Ms. 7, 8 y 23 tienen la misma procedencia, aunque los dos primeros son más tempranos que el último. No obstante, tan sólo un análisis del contenido de las fuentes permite elaborar hipótesis más fundamentadas acerca de la cronología de las obras.

\section{DESCRIPCIÓN Y ANÁLISIS DEL CONTENIDO PARA DILUCIDAR SI EL ORDEN EN EL PAPEL ES CRONOLÓGICO}

Asumiendo que los manuscritos encuadernados fueran cuadernos de papel pautado, la pregunta siguiente es si Arce los usaba para ir escribiendo, o para pasar a limpio las obras que le gustaban o que quería conservar. La grafía esmerada que se ha mencionado más arriba indica que fue más bien lo segundo. Sin embargo, esta vez será el contenido, y no el continente, el que suministre más datos para salir de dudas. Además, algo que se ha perfilado en el estudio de los soportes es la posibilidad de que los manuscritos Ms. 7 y Ms. 8 los escribiera al mismo tiempo, mientras que el Ms. 22 va aparte y el Ms. 23 lo tuvo al final, durante los cuatro últimos años de su vida.

La herramienta que se ha usado para buscar patrones cronológicos, o por lo menos un mínimo orden o coherencia, son las tablas-resumen. La primera columna recoge el número total de obras dentro de un mismo grupo, especificado en la segunda columna,

13 Para más detalles sobre las diferencias entre la grafía esmerada y la cursiva de José Martínez de Arce, véase: Mateo Sabadell, C. (2016). 


\section{Clara MATeo SABADEll}

dedicada a la advocación. Después, se detalla el número de folios que abarca el grupo y, por último, las fechas, si constan. Si hay varias obras seguidas compuestas en un mismo año, solo se copia el año una vez. Las fechas de las obras en las que consta el año se han escrito respetando el orden en que aparecen en la fuente y dos guiones indican ausencia de año. Las obras en latín se han agrupado sin hacer distinciones de forma.

En primer lugar, se presenta el manuscrito Ms. 8, porque las obras que aparecen en su interior son más tempranas. Por ejemplo, en la tabla de la Fig. 11 se ve cómo los treinta primeros folios del manuscrito Ms. 8 contienen 18 obras para diversas Vírgenes, fechadas entre 1699 y 1705.

\begin{tabular}{|c|l|l|l|}
\hline Cantidad & \multicolumn{1}{|c|}{ Advocación } & \multicolumn{1}{|c|}{ Folios } & \multicolumn{1}{c|}{ Años } \\
\hline 18 & Virgen (variadas) & $1-30 \mathrm{v}$ & $1699,--, 1702,1703,1704,1705$ \\
\hline 1 & Clarines sueltos a dúo & $31-32 \mathrm{v}$ & -- \\
\hline 2 & Virgen (1), Cruz (1) & $33-34 \mathrm{v}$ & $1706,--$ \\
\hline 8 & Navidad & $35-61 \mathrm{v}$ & $1706,--, 1703,1699$ \\
\hline 1 & San Pedro & $62-64$ & -- \\
\hline 12 & Navidad & $64 \mathrm{v}-95 \mathrm{v}$ & $1699,--, 1700$ \\
\hline 2 & Navidad, Calenda & $96-105$ & 1700,1701 \\
\hline 2 & Sin advocación & $105-106$ & -- \\
\hline 9 & Navidad & $106 \mathrm{v}-127 \mathrm{v}$ & $1701,--, 1702$ \\
\hline 37 & Santísimo & $128-207$ & $--, 1700,1701,1702,1703,1704,1708$ \\
\hline 4 & Navidad & $207 \mathrm{v}-215$ & $1704,--, 1705$ \\
\hline 5 & Santísimo & $215-223$ & 1705 \\
\hline 4 & Navidad & $223 \mathrm{v}-234 \mathrm{v}$ & $1705,--$ \\
\hline 4 & Santísimo & $235-240 \mathrm{v}$ & -- \\
\hline 2 & Navidad & $241-245 \mathrm{v}$ & 1707,1710 \\
\hline
\end{tabular}

Fig. 11. Tabla-resumen con el contenido del Ms. 8 (Elaboración propia).

Un análisis detenido de la tabla que se muestra en la Fig. 11 pone en evidencia una lógica interna que pasaría desapercibida con un índice. Desde el principio hasta el folio 207 (resaltado en la tabla), las obras contenidas en este volumen se dividen en tres grandes $\operatorname{grupos}^{14}$ :

- 20 villancicos a la Virgen, para los años 1699, 1702-1706.

14 Para percibir el conjunto con más claridad se han excluido de los grupos el dúo de clarines (ff. 31-32v), el villancico a la Cruz (f. 34v), el villancico a San Pedro (ff. 62-64) y los dos villancicos sin advocación (ff. 105106). 


\section{LOS MANUSCRITOS ENCUADERNADOS DE JOSÉ MARTÍNEZ DE ARCE (CA. 1662-1721)}

- 31 villancicos de Navidad, para los años 1699, 1700-1703 y 1706.

- 37 villancicos al Santísimo, para los años 1700-1704 y 1708.

A partir del vuelto del folio 207 el orden cambia, ya que se alternan villancicos navideños y al Santísimo, entre cuatro y cinco de cada, de los años 1704, 1705, 1707 y 1710.

El estudio de la ubicación de los folios en blanco no ha revelado ninguna pauta coherente en su uso como separadores de años o advocaciones. Arce sólo dejó en blanco los vueltos de algunos folios, aparentemente con el fin de comenzar la obra siguiente en el recto del folio subsecuente. Sin embargo, estos espacios blancos se volvían preciados cuando el papel escaseaba. Ejemplo de ello son las obras añadidas con posterioridad, aprovechando precisamente esas páginas en blanco, o las mitades inferiores de los folios. Este es el caso del villancico para la Navidad de 1704 en el folio 90, que se encuentra en medio de una serie de siete villancicos navideños todos con fecha de 1700.

Las últimas obras de este manuscrito están fechadas en 1710. Lo más probable es que, una vez acabado, Arce utilizara simultáneamente el Ms. 22 (para obras de 1710 y 1711) y el Ms. 7, que reservaría durante un tiempo exclusivamente para las obras en latín y luego (cuando se terminó el Ms. 22) para el resto de las obras que él consideraba importantes. Para reforzar esta teoría, se presenta primero el Ms. 22 y luego el 7, mucho más complejo.

Como ya se ha visto, el Ms. 22 es diferente, ya que parece un cuaderno empezado encontrado y continuado por Arce. Por eso, los nueve primeros folios tienen obras en latín de otros autores que no fueron compuestas por Martínez de Arce, cuyas obras comienzan justo después. En la figura incluida a continuación se puede ver cómo, por vez primera, las obras fueron copiadas con cierta coherencia cronológica, empezando por los villancicos navideños de 1710, seguidos de los de 1711 de la forma siguiente: 
Clara Mateo SABADELL

\begin{tabular}{|c|l|l|l|}
\hline Cantidad & \multicolumn{1}{|c|}{ Advocación } & \multicolumn{1}{c|}{ Folios } & \multicolumn{1}{c|}{ Años } \\
\hline 4 & Navidad & $9 \mathrm{v}-29 \mathrm{v}$ & 1710 \\
\hline 1 & Sin advocación & $29 \mathrm{v}-31$ & Sin año \\
\hline 1 & Miserere & $31 \mathrm{v}-32$ & 1711 \\
\hline 6 & Santísimo & $32 \mathrm{v}-47 \mathrm{v}$ & 1711 \\
\hline 2 & Profesión, velo & $51 \mathrm{v}-54 \mathrm{v}$ & 1711 \\
\hline 1 & Asunción & $56 \mathrm{v}-60$ & 1711 \\
\hline 3 & Santos y Virgen & $54 \mathrm{v}-62$ & Sin año \\
\hline 2 & Navidad & $61 \mathrm{v}-69$ & Sin año \\
\hline 2 & Navidad & $69 \mathrm{v}-83$ & 1711 \\
\hline
\end{tabular}

Fig. 12: Tabla-resumen con el contenido del Ms. 22 (Elaboración propia).

El número de obras sin fechar de este manuscrito es muy reducido. La distribución de las obras fechadas en la fuente permite suponer que, por vez primera, Arce utilizó el libro para ir escribiendo las obras según iba necesitándolo durante el año litúrgico y no separándolas por advocaciones o de una manera más irregular. Por esta razón, lo más seguro es que las cinco obras sin año de los últimos folios sean de 1711. En todo caso, no parece demasiado arriesgado afirmar que todas las obras contenidas en este volumen fueron escritas en 1710 y 1711.

No sucede lo mismo con el manuscrito Ms. 7, a cuyo contenido no se ha encontrado ninguna lógica inmediata. Este volumen encuadernado contiene obras desde 1702 hasta 1713. Si se fija la atención en las compuestas en los años 1710 hasta 1713, destacadas en la figura más abajo, se puede intuir una lógica más bien por advocación que por años, pero no muy coherente. Primero una obra en latín con fecha de 1713, después villancicos a diversas Vírgenes de 1710, seguido de una lamentación en latín con la misma fecha; por último, una sucesión de villancicos navideños, al Santísimo y a la Virgen. El desorden en la distribución de algunas obras como el villancico a la Virgen de la Asunción (f. 196) se debe a que no estaba escrita usando el folio completo, sino aprovechando pentagramas en blanco que les sobraban a otras obras. 
Los MANUSCRitos ENCUADERnAdos DE José MARTÍNEZ DE ARCE (CA. 1662-1721)

\begin{tabular}{|c|c|c|c|}
\hline Cantidad & Advocación & Folios & Años \\
\hline 17 & Latín & $1-44 \mathrm{v}$ &,-- 1713 (sólo 1) \\
\hline 3 & Navidad & $45-48 v$ & $1702,--$ \\
\hline 6 & Latin & $49-62 \mathrm{v}$ & $1709,1704,--$ \\
\hline 3 & Virgen & 63-68 & $1707,1710,--$ \\
\hline 1 & Stos. Cosme y Damián & $65 \mathrm{r}-\mathrm{v}$ & -- \\
\hline 1 & Naridad & 66 & 1710 \\
\hline 1 & Virgen & $68 \mathrm{v} ; 69-71$ & 1710 \\
\hline 1 & Santísimo & $71 \mathrm{v}-72 \mathrm{v}$ & -- \\
\hline 3 & Navidad & $73-83$ & $1707,--, 1708$ \\
\hline 3 & Santísimo & $83 \mathrm{v}-86$ & 1708 \\
\hline 1 & Virgen & $86 v-88$ & 1710 \\
\hline 1 & Lamentación, latin & $88 v-90 v ; 96 v-100 v$ & 1710 \\
\hline 2 & Navidad & $91-94 \mathrm{v}$ & 1712,1713 \\
\hline 1 & Virgen & $95-96$ & -- \\
\hline 11 & Latín & $101-129 \mathrm{v}$ & -- \\
\hline 1 & Virgen & $130-131$ & 1708 \\
\hline 5 & Santísimo & $131 \mathrm{v}-138$ & $1709,--$ \\
\hline 2 & Navidad & $140-143 \mathrm{v}$ & 1711,1713 \\
\hline 2 & Latín & $144-157 \mathrm{v}$ & -- \\
\hline 1 & Navidad & $158-165 \mathrm{v}$ & 1708 \\
\hline 1 & Sin advocación & $158-162$ & -- \\
\hline 1 & Miserere & $162 \mathrm{v}-168^{\circ}$ & -- \\
\hline 2 & Navidad & $165 \mathrm{v}-169$ & 1708,1709 \\
\hline 1 & Sta. Catalina & $169 \mathrm{v}$ & 1709 \\
\hline 3 & Naridad & $170-175 \mathrm{v}$ & $1709,--$ \\
\hline 2 & Latín & $176-184$ & -- \\
\hline 1 & Sin advocación & $184 \mathrm{v}$ & -- \\
\hline 1 & Virgen Sagrario & $185 r-v$ & -- \\
\hline 2 & Latín, difuntos & $186-187 \mathrm{v}$ & - \\
\hline 1 & Navidad & $188-189 \mathrm{v}$ & 1710 \\
\hline 1 & Latín, Reyes & $190 \mathrm{r}-\mathrm{v}$ & 1690 \\
\hline 2 & Santísimo & $191-195 \mathrm{v}$ & 1710 \\
\hline 1 & Virgen, Asunción & $196 \mathrm{r}-\mathrm{v} / / 195 \mathrm{v} / / 195$ & 1710 \\
\hline 4 & Naridad & $197-202$ & 1705 \\
\hline 1 & Virgen, Sagrario & $202 \mathrm{v}-204 \mathrm{v}$ & 1707 \\
\hline 4 & Santísimo & $205-213$ & $1707,--$ \\
\hline 1 & Virgen & $214-215$ & 1710 \\
\hline 2 & Santísimo & $215 \mathrm{v}-219 \mathrm{v}$ &,-- 1710 \\
\hline
\end{tabular}

Fig. 13: Tabla-resumen con el contenido del Ms. 7 (Elaboración propia).

La inscripción del lomo y los 63 primeros folios (exceptuando cuatro con obras en castellano) indican que Arce quería usar este volumen para recopilar las obras en latín. Sin embargo, después empezó a copiar también aquí villancicos en castellano al Santísimo, a la Virgen, a diversos Santos y para la noche de Navidad. Aunque no del todo, las fechas son ligeramente posteriores a las del Ms. 8. Por lo tanto, tal vez estuviera varios años copiando las obras en castellano en el Ms. 8 y las obras en latín en el Ms. 7, hasta que el primero se 


\section{Clara MATeo SABADEll}

terminó y entonces amplió el uso del segundo también para albergar villancicos. En lo que al Ms. 22 respecta, casi todas las obras fechadas que contiene datan de 1711. Este año está ausente en el Ms. 8 y solo aparece una vez en el Ms. 7, mientras que ambos sí contienen obras de 1710. Por lo tanto, lo más probable es que durante el año 1711 Arce usara casi de manera exclusiva el Ms. 22 y luego volviera al Ms. 7, ya que las páginas del Ms. 8 se habían terminado.

Las fuentes conservadas sugieren que cuando se acabaron las páginas de todos los manuscritos encuadernados (incluidos los espacios en blanco), Arce tuvo que volver a los papeles sueltos, entendiendo por tales a las manos de borrador con el mismo formato, pero sin encuadernar. Fue en los últimos cuatro años de su vida cuando volvió a contar con un manuscrito encuadernado, en el que recogió la gran mayoría del repertorio de estos años: el Ms. 23. Es cierto que, como indica Antonio Ezquerro (2002), los papeles sueltos y los manuscritos encuadernados tenían finalidades diversas, siendo de índole más práctica los primeros y con fines de conservación los segundos. Sin embargo, en el caso del repertorio contenido en las fuentes aquí estudiadas, con un número de voces y complejidad bastante elevado, es difícil que estas manos de borrador fueran usadas por los músicos durante la interpretación. Lo menudo de la grafía haría necesarias las partichelas.

En lo que al contenido respecta, hay tres factores que indican que Arce utilizó este libro como si de un cuaderno se tratase, copiando las obras a medida que las iba escribiendo, es decir, siguiendo un orden cronológico.

El primer indicio es la ubicación de las obras fechadas que, unida a la advocación de las que no lo están, revela un orden interno bastante coherente que está resumido en la Figura 12. Aunque no se ha hecho constar en la tabla, la posición de los villancicos de Calenda, que eran los primeros de la noche de Navidad, corrobora la teoría de que las obras sin año pueden ser fechadas según su ubicación en las fuentes, ya que, exceptuando la ausencia de este villancico en 1718 , se encuentran los primeros de las series navideñas para los años 1719 a 1721.

No obstante, hay algunas obras cuya ubicación en la fuente no es una pista válida para su datación. La disminución del número de voces de la plantilla en estos últimos años tuvo como resultado una mayor presencia de pentagramas vacíos en la zona inferior de los folios. A pesar de disponer de folios en blanco, Martínez de Arce aprovechó en ocasiones estos espacios para escribir obras enteras (también con muy pocas voces) en estos huecos. Este es el caso de Déjenme arrullar a mi Niño, obra escrita debajo de Si esta noche el contento (1718), aprovechando los seis pentagramas inferiores de los folios 13v-15 y 16v. En este caso, la datación lineal basada en la ubicación en la fuente no es tan obvia y tan sólo se puede fechar esta obra como compuesta entre 1718 y 1721. 
Los MANUSCRitos ENCUADERnAdos DE José MARTÍNEZ DE ARCE (CA. 1662-1721)

\begin{tabular}{|c|c|c|c|c|}
\hline $\begin{array}{l}\mathrm{N}^{\circ} \text { de } \\
\text { obras }\end{array}$ & Advocación & Folios & \multicolumn{2}{|c|}{ Año } \\
\hline 2 & Virgen (latín) & $1-4 \mathrm{v}$ & 1718 & \multirow{5}{*}{$\begin{array}{l}1 \\
7 \\
1 \\
8\end{array}$} \\
\hline 4 & Navidad, Nacimiento & $5-16$ & 1718 & \\
\hline 1 & Navidad, Nacimiento & $13 \mathrm{v}-15 / / 16 \mathrm{v}-17 \mathrm{v}$ & - & \\
\hline 3 & Navidad, Nacimiento & $16 \mathrm{v}-23 \mathrm{v}$ & 1718 & \\
\hline 1 & "Música para un festejo» & $24-27$ & -- & \\
\hline & En blanco & $27 \mathrm{v}$ & & \\
\hline 1 & Lamentación (latín) & $28-29 \mathrm{v}$ & 1719 & \multirow{9}{*}{$\begin{array}{l}1 \\
7 \\
1 \\
9\end{array}$} \\
\hline 5 & Santísimo & $30-43$ & 1719 & \\
\hline & En blanco & $43 \mathrm{v}$ & & \\
\hline 1 & Santísimo [incompleta] & 44 & 1720 & \\
\hline & En blanco & $44 v-46 v$ & & \\
\hline 1 & Navidad, Reyes & $47-49 \mathrm{v}$ & 1719 & \\
\hline 4 & Navidad, Nacimiento & $50-59$ & 1719 & \\
\hline 1 & Navidad, Nacimiento & $59 \mathrm{v}-60 \mathrm{v}$ & -- & \\
\hline 6 & Navidad, Nacimiento & $61-73$ & 1719 & \\
\hline 1 & Virgen, Sagrario & $73 v-75$ & 1720 & \multirow{9}{*}{$\begin{array}{l}1 \\
7 \\
2 \\
0\end{array}$} \\
\hline & En blanco & $75 \mathrm{v}-76 \mathrm{v}$ & & \\
\hline 1 & Santísimo & $77-79$ & 1720 & \\
\hline \multirow[t]{2}{*}{10} & Santísimo & $79-92$ & -- & \\
\hline & En blanco & $92 \mathrm{v}-93 \mathrm{v}$ & & \\
\hline 1 & $\begin{array}{l}\text { Santos Ramón y Fco. } \\
\text { Javier }\end{array}$ & $94 \mathrm{r}-\mathrm{v}$ & -- & \\
\hline 3 & Navidad, Nacimiento & $95-109$ & 1720 & \\
\hline 3 & Navidad, Nacimiento & $109-117$ & -- & \\
\hline 5 & Navidad, Nacimiento & $117-124 \mathrm{v}$ & 1720 & \\
\hline 2 & Santísimo & $125-127 \mathrm{v}$ & 1721 & \multirow{9}{*}{$\begin{array}{l}1 \\
7 \\
2 \\
1\end{array}$} \\
\hline 9 & Santísimo & $128-142$ & -- & \\
\hline & En blanco & $142 \mathrm{v}$ & & \\
\hline 1 & Navidad, Nacimiento & $143-149$ & 1721 & \\
\hline 2 & Navidad, Nacimiento & $149-153$ & - & \\
\hline 1 & Navidad, Nacimiento & $153 \mathrm{v}-155$ & 1721 & \\
\hline 1 & Navidad, Nacimiento & $155-160 \mathrm{v}$ & -- & \\
\hline 4 & Navidad, Nacimiento & $161-170 \mathrm{v}$ & 1721 & \\
\hline 1 & Navidad, Nacimiento & $170 \mathrm{v}-172 \mathrm{v}$ & -- & \\
\hline
\end{tabular}

Fig. 14: Tabla-resumen con el contenido del Ms. 23 (Elaboración propia)

El segundo indicio de una confección más ordenada del manuscrito son los intervalos con folios en blanco (destacados en gris en la Figura 14), cuya presencia no es tan aleatoria como parece. El papel en aquel entonces era un bien preciado, máxime el de este manuscrito encuadernado, que era de buena calidad, y por esta razón resulta difícil comprender por qué José Martínez de Arce dejó folios completos sin escribir. Lo más lógico es pensar que los tenía destinados para obras que no llegó a copiar, como la obra incompleta al Santísimo del folio 44. Sin embargo, con una observación más detenida de la tabla se puede apreciar que siguen un patrón muy concreto y que fueron usados como separadores entre obras de distinto año y, sobre todo, de diferente advocación. 


\section{Clara Mateo Sabadell}

La tercera y última pista que apoya la hipótesis del orden cronológico de las obras en el manuscrito procede de fuentes externas. Se trata de dos pliegos que contienen los textos de los villancicos interpretados en la Capilla Real las noches de Navidad de 1719 y 1720 . En las dos tablas contenidas en la Figura 15 se puede ver por vez primera la casi total correspondencia no sólo de los títulos, sino del orden que ocupan en ambas fuentes.

A. Correspondencias de las obras del Ms. 23 con los pliegos de la Capilla Real (1719)

\begin{tabular}{|c|c|l|l|}
\hline $\begin{array}{c}\text { No } \\
\text { CT. }\end{array}$ & $\begin{array}{c}\text { Vc } \\
\text { o. }\end{array}$ & \multicolumn{1}{|c|}{$\begin{array}{c}\text { Título } \\
\text { (en VBN/B: 774) }\end{array}$} & \multicolumn{1}{|c|}{$\begin{array}{c}\text { PosICIÓN EN «Ms. 23» } \\
\text { (1720) }\end{array}$} \\
\hline I & 1 & Qué dulces armonias (pp. mss) & $95-102$ \\
\hline & 2 & Céfiros pájaros (pp. mss) & $102 \mathrm{v}-105 \mathrm{v}$ \\
\hline & 3 & Desatado diluvio de nieve (pp. mss) & $106-109$ \\
\hline II & 4 & Abrasado querubín & $109-111$ \\
\hline & 5 & Si la misteriosa escala & {$[$ No está en el manuscrito] } \\
\hline & 6 & Oscura noche fría & $111-112 \mathrm{v}$ \\
\hline III & 7 & Claras luces, que ba nacido el esplendor & $112 \mathrm{v}-117$ \\
\hline
\end{tabular}

B. Correspondencias de las obras del Ms. 23 con los pliegos de la Capilla Real (1720)

\begin{tabular}{|c|c|c|c|}
\hline $\begin{array}{l}\text { No } \\
\text { CT. }\end{array}$ & $\begin{array}{l}\text { Vc } \\
\text { o. }\end{array}$ & $\begin{array}{c}\text { Título } \\
\text { (en VBN/B: } 777 \text { ) }\end{array}$ & $\begin{array}{c}\text { PosICIÓN EN «Ms. 23» } \\
\text { (1721) }\end{array}$ \\
\hline I & 1 & En tempestad furiosa & 143-149 \\
\hline & 2 & Rompa el aire, el día rompa & $149-151$ \\
\hline & 3 & $A$ dónde con tal insulto & $151-153$ \\
\hline II & 4 & Qué visteis pastores & $153 \mathrm{v}-155$ \\
\hline & 5 & Alfuego ragales & $155-160 \mathrm{v}$ \\
\hline & 6 & Quien alberga un peregrino & $161-162$ \\
\hline III & 7 & A la mejor perla & [No está en el manuscrito] \\
\hline
\end{tabular}

Fig. 15: Correspondencias de las obras del Ms. 23 con los pliegos de la Capilla Real (Elaboración propia).

Estas coincidencias textuales también son importantes porque indican que Arce, o alguien de la capilla cercano a él, tenía una relación muy inmediata con el centro más importante de la capital. Por aquel entonces era maestro de capilla José de Torres, quien se había hecho cargo del puesto de forma definitiva en torno a 1718, aunque desde 1712 componía la música para el culto en la Real Capilla. Según Yvonne Levasseur, citada por Paulino Capdepón, se conocen tan sólo 171 obras de este compositor, la gran mayoría en el Archivo Real de Palacio (Levasseur-de-Rebollo, en Capdepón Verdú, 1989: 114). El reducido número es debido al incendio del antiguo Alcázar Real que en 1734 afectó al 


\section{LOS MANUSCRITOS ENCUADERNADOS DE JOSÉ MARTÍNEZ DE ARCE (CA. 1662-1721)}

archivo de música de la capilla. Todavía no se ha encontrado ninguna de estas obras. Pendiente queda una búsqueda exhaustiva en los archivos americanos, donde es posible encontrar copias de lo perdido en el incendio. El libro de Gustavo Delgado sobre un manuscrito de Torres para la enseñanza del órgano (2010) muestra la vía de circulación de música desde la península hasta el virreinato de Nueva España, donde seguramente haya partituras sin estudiar de Martínez de Arce, o tal vez se encuentren las obras originales que se interpretaron en la Capilla Real con los textos reutilizados por Arce.

Las evidencias de comunicación con la capital no terminan en el folio 162, ya que los textos de los siguientes cuatro villancicos navideños proceden de sendos pliegos con fecha de 1720 interpretados en los conventos madrileños de la Encarnación y las Descalzas (Figura 16). La música en el siglo XVIII en ambos conventos ha sido estudiada por Paulino Capdepón (1997 y 1999). Sin embargo, no se han encontrado los títulos que parece claro fueron reutilizados por Martínez de Arce.

\begin{tabular}{|c|c|c|c|c|}
\hline Noct. & VCO. & PROCEDENCIA (1720) & Título & $\begin{array}{c}\text { POSICIÓN EN «Ms. 23» } \\
(1721)\end{array}$ \\
\hline II & 5 & Madrid, Descalzas ${ }^{11}$ & Con licencia de ustedes & $162 \mathrm{v}-164$ \\
\hline $\mathrm{I}$ & 2 & Madrid, Encarnación ${ }^{12}$ & Hetela, va con donaire & $164 \mathrm{v}-168 \mathrm{v}$ \\
\hline II & 7 & Madrid, Descalzas & Ande, gire, viele, corra & $169-170 \mathrm{v}$ \\
\hline II & 9 & Madrid, Descalzas & Al Niño precioso & $170 \mathrm{v}-172 \mathrm{v}$ \\
\hline
\end{tabular}

Fig. 16: Correspondencias del resto de villancicos navideños de 1721 (Elaboración propia).

El libro Ms. 23 es una importante herramienta de datación para el repertorio tardío, ya que ofrece pruebas bastante convincentes que permiten suponer que todas las obras en él contenidas fueron compuestas entre 1718 y 1721. Por esta misma razón, este volumen es intrigante, ya que su carácter cerrado y completo presenta a un José Martínez de Arce que dejó todo terminado antes de morir. Tal vez fuera su hermano Tomás quien procediera a la encuadernación de las obras de estos años tras la muerte de José. Otra posibilidad es que lo hiciera el propio Cabildo, a quien José había cedido toda su obra en su legado testamentario ${ }^{15}$.

\section{CONCLUSIONES}

Investigar a un compositor que vivió en tu ciudad hace trescientos años, hace que la curiosidad se avive. Cada vez que iba a la catedral y subía a la torre en la que está el archivo de música, no dejaba de pensar que tal vez, solo tal vez, José Martínez de Arce, también

15 Este legado ha desaparecido, pero es mencionado por Carmelo Caballero en la voz «Martínez de Arce, José» del DMEH. 


\section{Clara MATeo SABADEll}

había estado allí. Las mismas paredes nos protegían a uno y a otro, de las mismas inclemencias del tiempo, tan iguales y tan distintas al mismo tiempo.

Cuando abrí por primera vez los manuscritos encuadernados, que llevaban su nombre en el canto, me sentí todavía más maravillada; como si estuviera asomándome a una puerta que unía su mundo y el mío, separados en el tiempo por trescientos años, pero juntos en el espacio gracias a ese legado. Tal vez se deba a su carácter cerrado, o a su excepcional buen estado de conservación, o a las marcas que indican dónde ponía el dedo su propietario cada vez que lo abría, lo que hacían que estos cuatro volúmenes fueran mucho más fascinantes que los caóticos papeles sueltos y las ordenadas partichelas. Sea como fuere, desde que terminé la tesis, tenía pendiente dedicar mi atención a estas fuentes, que me intrigaban sobremanera y que yo sentía, me acercaban de manera más inmediata a mi objeto de estudio.

La primera pregunta que plantean estos cuatro libros es si el compositor trabajó con ellos cuando estaban ya encuadernados, o si se trata de una recopilación de obras pasadas a limpio en papeles sueltos. El estudio pormenorizado de las medidas y la encuadernación lleva a pensar que los manuscritos Ms. 7, Ms. 8 y Ms. 23 fueron usados como cuadernos. Además, las grandes similitudes observadas apuntan a que se los compró los tres a un mismo artesano, tal vez los dos primeros en primer lugar y el tercero alrededor de 1718. Sin embargo, la falta de coincidencia entre el número de folios de cada volumen y el carácter cerrado del Ms. 23 (que no tiene páginas en blanco y cuyo contenido termina a la vez que la vida del compositor) hacen que la hipótesis del compendio sea imposible de descartar. Por otro lado, las características físicas del Ms. 22, así como el hecho de contener ya varias obras en latín, indican que podría haberlo comprado aparte, o bien haberlo encontrado en su centro de trabajo para reciclarlo y así copiar sus villancicos, cuya grafía no se adapta del todo al amplio rastro del repertorio en latín.

La segunda pregunta se centraba en los folios y buscaba saber si Arce los compró previamente rayados o si diseñaba él mismo las páginas. La homogeneidad en la composición de las páginas lleva a pensar que lo más seguro es que comprara los pliegos, o los cuadernos, con hojas pautadas.

Por último, desde el punto de vista musicológico, lo más interesante ha sido buscar patrones o pautas de copia que permitan dar unas fechas aproximadas de las obras contenidas en los manuscritos. La herramienta de las tablas-resumen ha sido de gran ayuda, así como los gráficos en los que se analiza la distribución de las obras en los soportes. Se ha visto cómo el uso de los manuscritos encuadernados empezó en 1699, cuando comenzó a usar el Ms. 7 y el Ms. 8. Hasta 1710 el primero empezó conteniendo las obras en latín, mientras el segundo contenía las obras en romance. Sin embargo, con los años, este principio se fue desdibujando. En 1710 hizo su aparición el Ms. 22, que se llenó de obras sobre todo de 1711. A partir de ese año y hasta 1717 volvió a utilizar tan solo papeles sueltos. En último lugar hizo su aparición el Ms. 23, que contiene muy ordenadas las obras escritas entre 1718 y el año de su muerte, 1721. Este volumen es especialmente llamativo, por lo ordenado del repertorio que contiene, así como por el elevado número de correspondencias con dos pliegos de villancicos interpretados en la Capilla Real los años 


\section{LOS MANUSCRITOS ENCUADERNADOS DE JOSÉ MARTÍNEZ DE ARCE (CA. 1662-1721)}

inmediatamente anteriores. No obstante, queda pendiente un estudio más riguroso de las grafías, así como una comparación con fuentes coetáneas a las estudiadas, que tome como modelo metodológico las recientes tesis doctorales de Salisis i Clos (2012), Yáñez Navarro (2016) y Canela Grau (2017).

También sería necesario llevar a cabo un estudio de las marcas de agua. El Dr. Antonio Ezquerro (2000) pone de relieve la necesidad de estudiar las marcas de agua del papel, para facilitar no solo su datación, sino también para identificar procesos de intercambio y elaborar mapas de difusión de dicho papel. Los folios encuadernados en los volúmenes aquí estudiados tienen, algunos de ellos, marcas de agua, cuyo detallado estudio podría sin duda ser protagonista de otro artículo, aún por escribir. En esta línea se puede tomar como punto de partida el estudio más reciente llevado a cabo por la Dra. Montserrat Canela Grau, en su tesis doctoral, donde estudia las marcas de agua en las obras de Antoni Milà (2017, pp. 501-534).

Una de las conclusiones más importantes que se extraen del análisis de estas fuentes proviene de la comprensión de su finalidad. Parece bastante claro que se trata de partituras de obras que el compositor, o en el caso del Ms. 23, sus sucesores, quieren conservar. Lo interesante es que no son solo obras en latín, como sucedía en las copias "de archivo" estudiadas por Ezquerro (2001), sino que hay un número muy elevado de villancicos. Esto puede ser visto como síntoma de un cambio importante en la percepción del género. El hecho de que se encuadernen estas obras es muestra de cómo esta forma va perdiendo su carácter efímero, que Ezquerro (2001) afirma condicionaba su proceso de copia (p. 16), ya que, si la obra iba a durar pocos días, "no merecía gastar más de lo imprescindible, en papel, encuadernaciones, [...] etc.". Todo apunta a una reutilización del material y, por lo tanto, a una disminución paulatina de la composición de villancicos originales.

A pesar de todo lo dicho, los manuscritos encuadernados Ms. 7, 8, 22 y 23 siguen planteando más preguntas que respuestas. Pendiente queda saber qué artesano (o artesanos) los realizó. Para despejar la incógnita de si son cuadernos o compendios de obras encuadernados a posteriori será necesario un estudio codicológico de los cuatro volúmenes, realizado por un experto, con la formación y utensilios necesarios. Tal vez esto permitiría fechar con más precisión algunas obras, cuya posición en los libros siembra de dudas la débil lógica encontrada tras la aplicación de las tablas-resumen. En todo caso, no cabe duda de que estos cuatro volúmenes son un tesoro digno de conservar, preservar y, por supuesto, difundir para el estudio e interpretación de las 304 obras que contienen. 


\section{Clara MATeo SABADEll}

\section{BIBLIOGRAFÍA}

Aizpurúa Zalacaín, P. (1988). Música y músicos de la catedral metropolitana de Valladolid. Valladolid: Real Academia de Bellas Artes de la Purísima Concepción de Valladolid. Anglés, H. (1948). "El Archivo Musical de la Catedral de Valladolid”. Anuario Musical, III, pp. $59-108$.

Artero, J. (1947). “Oposiciones al Magisterio de Capilla en España durante el siglo XVIII”. Anuario Musical, II, pp. 191-202.

Bande Rodríguez, E. y Tain Carril, C. (2000): Arcbivo Histórico Diocesano de Ourense. Inventario de fondos parroquiales. Orense: Diputación Provincial de Orense.

Caballero Fernández-Rufete, C. (1994). Miguel Gómez Camargo (1618-1690). Biografía, legado testamentario y estudio de los procedimientos paródicos en sus villancicos. Valladolid: Tesis Doctoral inédita.

Caballero Fernández-Rufete, C. (1999). “Martínez de Arce, José”, en E. Casares (dir.). Diccionario de la Música Española e Hispanoamericana, vol. 7, pp. 273-275. Madrid: Iberautor.

Canela Grau, M. (2017). Antón Milá, tres décadas de paisaje sonoro devocional. Estudio sobre la capilla de música y el compositor tarraconense en la segunda mitad del siglo XVIII. Tesis doctoral. Salamanca: Universidad de Salamanca.

Capdepón Verdú, P. (1997). La música en el Real Monasterio de la Encarnación (siglo XVIII). Madrid: Fundación Especial Caja Madrid.

Capdepón Verdú, P. (1999). La música en el Monasterio de las Descalzas Reales (siglo XVIII). Madrid: Fundación Especial Caja Madrid.

Carreras, J. J. (2001). "Cantata”, en S. Sadie y J. Tyrrell (eds.). New Grove Dictionary of Music and Musicians, vol. 5, pp. 37-40. Oxford: Oxford University Press.

Delgado Parra, G. (2010). Un libro didáctico del siglo XVIII para la enseñanza de la composición. Valencia: Universidad Politécnica de Valencia.

Ezquerro Esteban, A. (2000). "El estudio de las marcas de agua del papel como material para determinar la datación y procedencia de las fuentes histórico-musicales y su grado de fiabilidad". Anuario Musical, 55, pp. 19-69.

Ezquerro Esteban, A. (2001). "Casos curiosos, peculiaridades y formas alternativas de anotar la música en el área hispánica en el siglo XVII. Procesos de intercambio entre lo culto y lo popular". Anuario Musical, 56, pp. 97-113. 
LOS MANUSCRITOS ENCUADERNADOS DE JosÉ MARTÍNEZ DE ARCE (CA. 1662-1721)

Ezquerro Esteban, A. (2002). "Tabula compositoria, partitura, chapa y borrador. Formas de anotar la polifonía y música instrumental en el ámbito hispánico durante el periodo barroco", en Paul Mai (ed), Im Dienst der Quellen zur Musik. Festschrift Getraut Haberkamp zum 65 Geburtstag. Tutzing: Hans Schneider Verlag.

Guillén Bermejo, C. y Ruiz Serra, I. (1990). Catálogo de villancicos y oratorios en la Biblioteca nacional: siglos XVIII-XIX. Madrid: Ministerio de Cultura, Dirección General del Libro y Bibliotecas.

Levasseur-de-Rebollo, Y. (1975). The life and works Joseph de Torres Martinezy Bravo (16651738), citado por Capdepón Verdú, P. (1989). "La música en la Capilla Real de Madrid: S. XVIII". Anales del Instituto de Estudios Madrileños, no 27, p. 114.

López-Calo, J. (1988). Historia de la música española, 3, siglo XVII. Madrid: Alianza Música.

López-Calo, J. (2007). La música en la Catedral de Valladolid, 8 vols. Valladolid: Ayuntamiento de Valladolid, Caja España.

Martín Moreno, A. (2001). Historia de la música española, 4, Siglo XVIII. Madrid: Alianza Música.

Mateo Sabadell, C. (2016). El cambio de estilo en los villancicos de José Martínez de Arce (ca. 16621721). Tesis doctoral. Valladolid: Universidad de Valladolid.

Sabe Andreu, A. Ma (2012). La capilla de música de la catedral de Ávila (siglos XV al XVIII). Ávila: Diputación Provincial de Ávila e Institución Gran Duque de Alba.

Salisi i Clos, J.M. (2012). El repertori litúrgic marià a Catalunya a finales del segle XVII. (Les antifones marianes majors de l'M 1168 del «Fons Verdú» de la Biblioteca de Catalunya. Tesis doctoral. Barcelona, Universidad Autónoma de Barcelona.

Virgili Blanquet, Ma A. y Caballero Fernánez-Rufete, C. (1996). "La música religiosa en la diócesis vallisoletana", en Historia de la diócesis de Valladolid, pp. 604-606. Valladolid: Arzobispado Diputación Provincial.

Yáñez Navarro, C. (2016). Nuevas aportaciones para el estudio de las Sonatas de Domenico Scarlatti. Los manuscritos del Archivo de Música de las Catedrales de Zaragoza. Tesis doctoral. Barcelona: Universidad Autónoma de Barcelona.

Fecha de recepción: 12/03/2018

Fecha de aceptación: 25/05/2018 